\title{
Canadian Digestive Health Foundation Public Impact Series 5: Pancreatitis in Canada. Incidence, prevalence, and direct and indirect economic impact
}

\author{
Christopher W Teshima MD FRCPC ${ }^{1}$, Ronald J Bridges MD FRCPC ${ }^{2}$, Richard N Fedorak MD FRCPC ${ }^{1}$
}

\begin{abstract}
CW Teshima, RJ Bridges, RN Fedorak. Canadian Digestive Health Foundation Public Impact Series 5: Pancreatitis in Canada. Incidence, prevalence, and direct and indirect economic impact. Can J Gastroenterol 2012;26(8):544-545.
\end{abstract}

The Canadian Digestive Health Foundation initiated a scientific program to assess the incidence, prevalence, mortality and economic impact of digestive disorders across Canada in 2009. The current article presents the updated findings from the study concerning pancreatitis.

Key Words: Canada health care; Burden of disease; Digestive disease; Epidemiology; Health economics; Pancreatitis

\section{Cinquième article de la série sur les répercussions sur le public de la Fondation canadienne pour la promotion de la santé digestive : l'incidence, la prévalence et les conséquences économiques directes et indirectes de la pancréatite}

En 2009, la Fondation canadienne pour la promotion de la santé digestive a lancé un programme scientifique pour évaluer l'incidence, la prévalence, la mortalité et les conséquences économiques des maladies digestives au Canada. Le présent article expose les observations mises à jour de l'étude sur la pancréatite.

studies from developed countries. Additional information was retrieved from government sources and not-for-profit organizations.

\section{INCIDENCE}

The peak incidence of pancreatitis for both men and women is between 40 and 70 years of age, with a male predominance in all age groups (3). Several studies conducted between 1981 and 2001 found that the incidence of first attacks of acute pancreatitis ranged from 9.8 to 37.8 per 100,000 individuals (3). The most recent epidemiological study conducted in California in 2001 (4) found that the incidence was as high as 43.8 per 100,000 , possibly due to increased clinical awareness of the disease and improved testing. Although less well studied, the available data from western countries regarding chronic pancreatitis suggest an incidence of six per 100,000 individuals (3). Using 2010 demographic data for Canada (population 34,482,779), approximately 15,100 and 2070 Canadians will be diagnosed with acute and chronic pancreatitis, respectively, in the coming year (5).

\section{PREVALENCE}

The proportion of patients with a first attack of pancreatitis who progress to chronic pancreatitis is estimated to be $6.5 \%$, while $16.5 \%$ will experience recurrent acute pancreatitis (6). Based on a 2011 study conducted in Olmstead County, Minnesota (USA) (7), the prevalence of chronic pancreatitis, adjusted for age and sex, was determined to be 41.6 per 100,000 inhabitants. Extrapolating this figure to the Canadian population means that there are 14,400 individuals living with chronic pancreatitis in this country.

\section{MORTALITY}

While overall mortality from acute pancreatitis has seen steady improvements and is now at $5 \%$, the mortality from necrotizing pancreatitis is much higher $(17 \%)$, and some studies have found rates as high as $30 \%$ within the subgroup of patients with severe acute pancreatitis $(8,9)$. For patients with chronic pancreatitis, a populationbased epidemiological study conducted in Olmstead County with a 10 -year follow-up period found an all-cause mortality rate of $44 \%$, which was significantly higher $(\mathrm{P}<0.001)$ than the age- and sexspecific expected mortality rate in Minnesota (7). However, chronic pancreatitis was considered to be the primary or contributing cause in

A systematic literature review was conducted to retrieve peerreviewed, scholarly literature published in English using the PubMed, MEDLINE, EMBASE and Scopus databases. The search term used was "pancreatitis", with a specific focus on epidemiology and economic

${ }^{1}$ Division of Gastroenterology, University of Alberta, Edmonton; ${ }^{2}$ Faculty of Medicine, University of Calgary, Calgary, Alberta
Correspondence: Dr Richard N Fedorak, 2-14A Zeidler Building, University of Alberta, Edmonton, Alberta T6G 2X8.

Telephone 780-492-6941, fax 780-492-8121,e-mail richard.fedorak@ualberta.ca

Received for publication December 7, 2011. Accepted December 20, 2011 
only $5 \%$ and $18 \%$ of deaths, respectively. In Canada, the annual number of deaths due to acute and chronic pancreatitis is 300 and 40 persons, respectively, (Figure 1) (10). For acute pancreatitis, nearly 10\% of all deaths are attributable to alcohol-induced pancreatitis, while deaths due to alcohol-induced chronic pancreatitis represent approximately $50 \%$ of cases (10).

\section{ECONOMICS}

\section{Direct costs}

The average length of hospital stay in Canada for patients with pancreatic conditions is 10 days. Between 1996 and 2005, this decreased to an average of eight days (11). In 2004/2005, the average cost per stay for pancreatic diseases was $\$ 8,896$, which for 13,200 patients resulted in a total cost of $\$ 118$ million (12). In comparison, $\$ 3.7$ billion was spent in the United States in 2004, with an average cost per hospitalization of $\$ 11,402(13,14)$. A German study noted that patients with chronic pancreatitis were prescribed daily analgesics (34\%), enzyme supplements (57\%), insulin (25\%) and oral diabetic medications $(4 \%)$, all of which contribute to considerable health care costs (15).

\section{Indirect costs}

Patients with acute and chronic pancreatitis report a decreased quality of life in many areas including physical restrictions and often suffer from long-term mental impairments (16). It is difficult to assess the actual indirect costs associated with pancreatitis due to the extensive comorbidities typical of this patient population (eg, diabetes, cardiovascular disease, smoking-related cancers and cirrhosis) and their cumulative effect on a person's productivity within society. Nevertheless, a

\section{REFERENCES}

1. Acute Pancreatitis Classification Working Group. Revision of the Atlanta classification of acute pancreatitis (3rd revision) [Pancreas Club website]. April 9, 2008. <www.pancreasclub.com/resources/ AtlantaClassification.pdf $>$ (Accessed November 9, 2011).

2. Steer ML, Waxman I, Freedman S. Chronic pancreatitis. New Engl J Med 1995;332:1482-90.

3. Spanier BW, Dijkgraaf MG, Bruno MJ. Epidemiology, aetiology and outcome of acute and chronic pancreatitis: An update. Best Pract Res Clin Gastroenterol 2008;22:45-63.

4. Frey CF, Zhou H, Harvey DJ, et al. The incidence and case-fatality rates of acute biliary, alcoholic, and idiopathic pancreatitis in California, 1994-2001. Pancreas 2006;33:336-44.

5. Statistics Canada. Population estimates by sex and age group as of July 2011, Canada. <www.statcan.gc.ca/start-debut-eng.html> (Accessed November 1, 2011).

6. Lankisch PG, Breuer N, Bruns A, et al. Natural history of acute pancreatitis: A long-term population-based study. Am J Gastroenterol 2009;104:2797-805.

7. Yadav D, Timmons L, Benson JT, et al. Incidence, prevalence, and survival of chronic pancreatitis: A population-based study. Am J Gastroenterol 2011;106:2192-9 (Erratum in 2011;106:2209).

8. Banks PA, Freeman ML; Practice Parameters Committee of the American College of Gastroenterology. Practice guidelines in acute pancreatitis. Am J Gastroenterol 2006;101:2379-400.

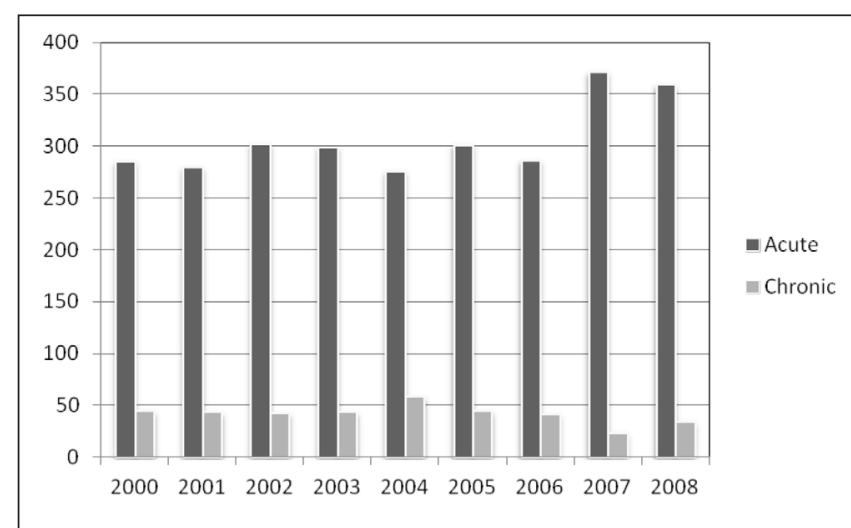

Figure 1) Number of Canadian mortalities due to pancreatitis (acute or chronic) according to year

German study of chronic pancreatitis patients (17) found that only $41 \%$ worked full-time and, of these, $40 \%$ had pancreatitis-related absences from work in the previous year. Interestingly, $14 \%$ took early retirement due to impairments associated with pancreatitis. Another case series of chronic pancreatitis patients reported that $12.1 \%$ were unable to work due to their illness and, as the disease progressed, it became more difficult for other patients to remain employed full-time (17). Thus, although data are not available to extrapolate the indirect costs of pancreatitis, it is clear that the burden of the illness on patients and their families is substantial.

9. Sarles H. Revised classification of pancreatitis - Marseille 1984. Dig Dis Sci 1985;30:573-4.

10. Statistics Canada. Table 102-0531 - Deaths, by cause, Chapter XI K00 to K93, age group and sex, Canada, 2000-2008. CANSIM. $<$ http://cansim2.statcan.gc.ca> (Accessed November 1, 2011).

11. Organisation for Economic Co-operation and Development (OECD). OECD Health Data 2008. < www.oecd.org> (Accessed November 1, 2011).

12. Canadian Institute for Health Information. The Cost of Acute Care Hospital Stays by Medical Condition in Canada: 2004-2005. ISBN 978-1-55465-216-7, 1-155. Ottawa: Canadian Institute for Health Information, 2008

13. Everhart JE, Ruhl CE. Burden of digestive diseases in the United States part I: Overall and upper gastrointestinal diseases. Gastroenterology 2009;136:376-86

14. Fagenholz PJ, Fernandez-del Castillo C, Harris NS, et al. Direct medical costs of acute pancreatitis hospitalizations in the United States. Pancreas 2007;35:302-7.

15. Wehler M, Nichterlein R, Fishcer B, et al. Factors associated with health-related quality of life in chronic pancreatitis. Am J Gastroenterol 2004;99:138-46.

16. Wu BU, Conwell DL. Update in acute pancreatitis. Curr Gastroenterol Rep 2010;12:83-90.

17. Jupp J, Fine D, Johnson CD. The epidemiology and socioeconomic impact of chronic pancreatitis. Best Pract Res Clin Gastroenterol 2010;24:219-31. 


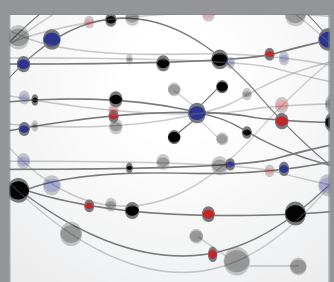

The Scientific World Journal
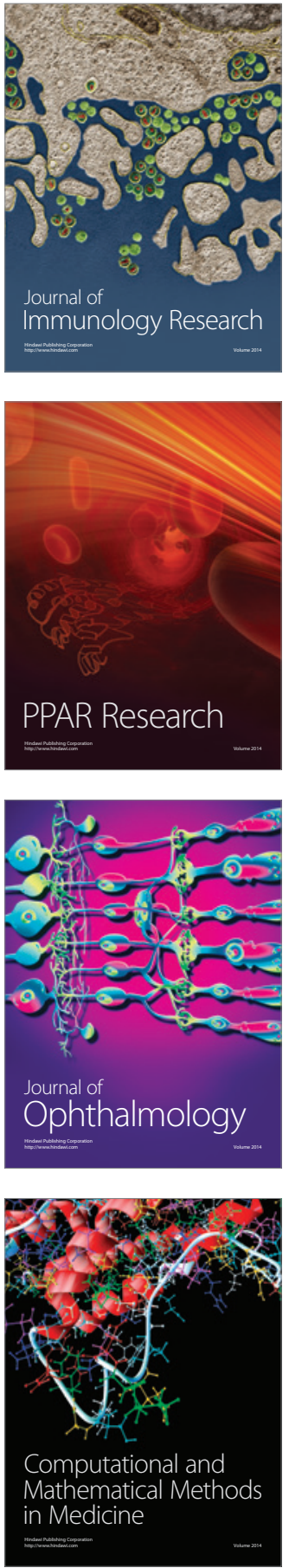

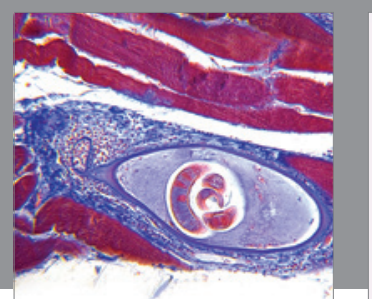

Gastroenterology Research and Practice

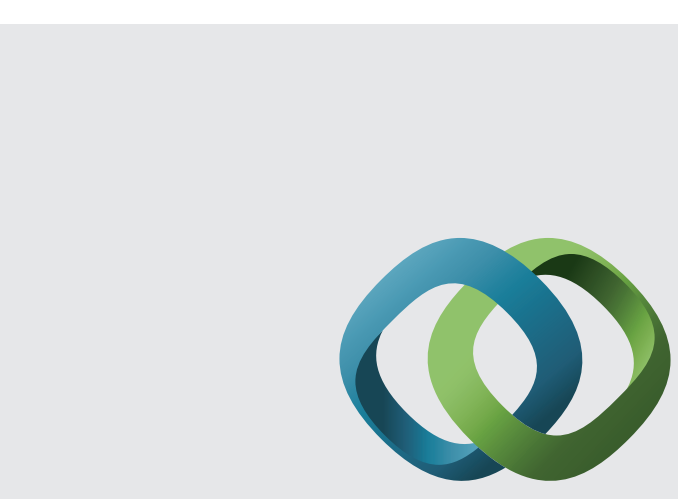

\section{Hindawi}

Submit your manuscripts at

http://www.hindawi.com
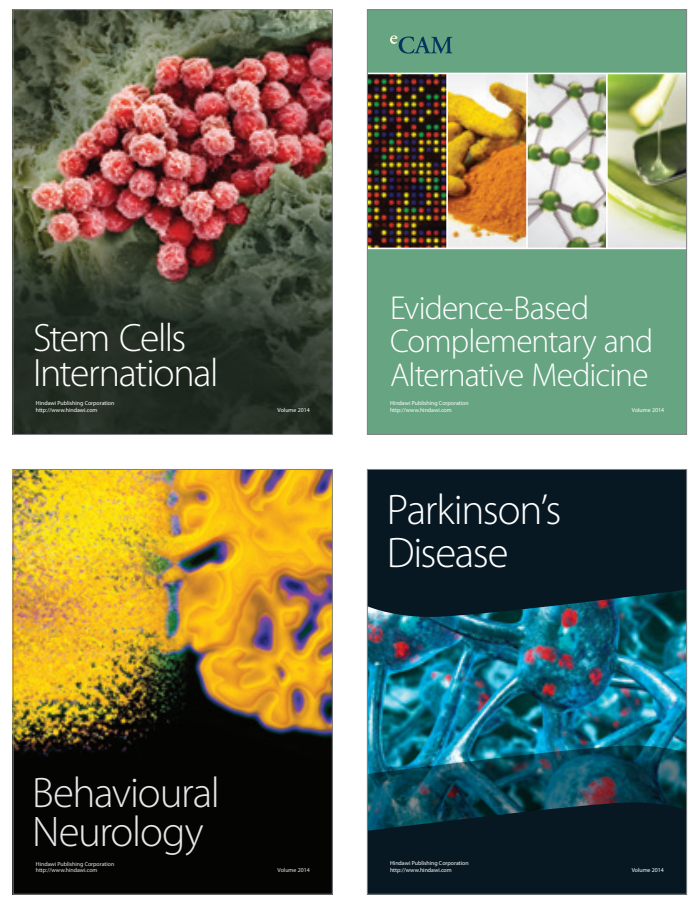
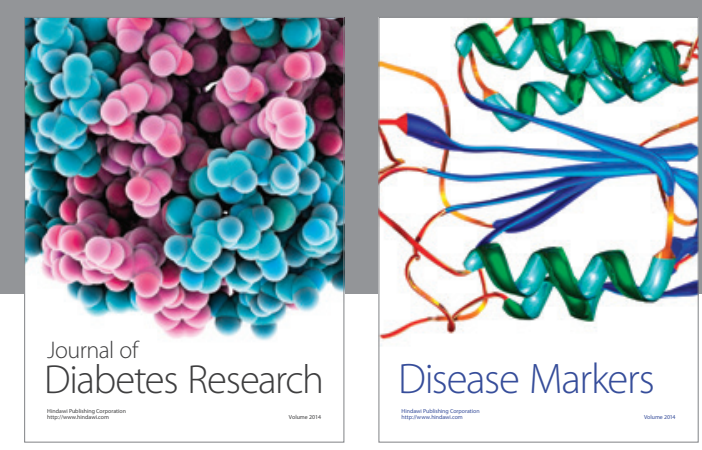

Disease Markers
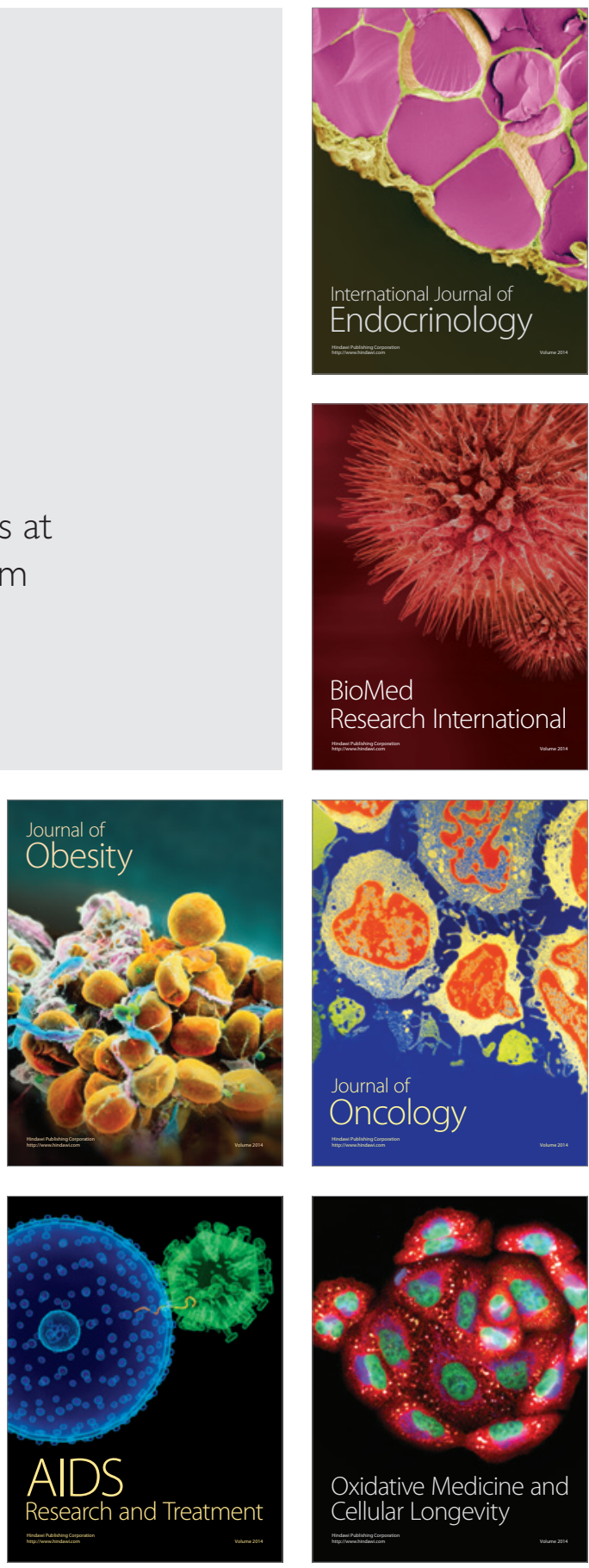